\title{
A hydrogeomorphological approach to quantification of groundwater discharge to streams in South Africa
}

\author{
Y X ${ }^{1 *}$, R Titus ${ }^{1}$, SD Holness ${ }^{1}, \mathrm{~J} \mathrm{Zhang}^{2}$ and GJ van Tonder ${ }^{3}$ \\ ${ }^{1}$ Department of Earth Sciences, University of the Western Cape, Private Bag X17, Bellville 7535, South Africa \\ ${ }^{2}$ Environmentek, CSIR, Stellenbosch, South Africa \\ ${ }^{3}$ Institute for Groundwater Studies, University of the Free State, Bloemfontein, South Africa
}

\begin{abstract}
In South Africa, the flow requirements for maintaining the normal functioning of aquatic ecosystems is termed the "ecological reserve", and these should be determined when a licence application for water allocation is processed. Determination of the ecological reserve entails investigation of the relationship between the major interactive components of the hydrologic cycle, namely groundwater and surface water bodies including rivers, lakes and estuaries. Information on groundwater discharge towards surface water bodies is critical for the water resource manager to make a decision regarding the amount of groundwater allocation that can be licensed without causing a negative impact on aquatic ecosystems. Existing techniques of hydrograph-separation are too subjective either due to the fact that assumptions of the techniques cannot be met in reality or that the parameters used in models do not have physical meanings. This paper presents a geomorphologic framework under which the quantification of groundwater from a hydrograph is discussed. A focus is placed on hydrogeomorphological typing that can be used to guide a process of separating groundwater discharge time series from hydrographs where a monthly groundwater discharge time series is required for comparison with instream flow requirements. For generating monthly groundwater discharge time series, a generic procedure is proposed, which is applied in a case study.
\end{abstract}

\section{Introduction}

The South African National Water Act of 1998 places emphasis on the protection of water resources for their sustainable utilisation. Officially, from the $1^{\text {st }}$ of October 1999 , a preliminary or comprehensive Reserve evaluation of a water management area should be determined when a licence application for water allocation is processed. The ecological reserve is a generic term representing flow requirements for aquatic ecosystems. In the case of rivers, it is referred to as the instream flow requirement (IFR). The fundamental assumption for the derivation of the IFRs is that rivers with a high degree of hydrological variability will require a lower proportion of their natural mean annual runoff, because they are accustomed to experiencing such conditions. In addition, the higher the desired conservation status is, the more instream flow is required.

Annual IFRs for high, low and drought flows are further assigned by hydrological and ecological specialists into 12 monthly values of the hydrological year from October to the following September. The 12 monthly values, often expressed in terms of various confidence levels, are based on generated instream flow time series (Hughes and Münster, 1999). The low flow component of the IFRs may be fed or maintained by groundwater discharge if there is hydraulic connection between aquifer and stream. Hence, groundwater allocation must take into account the possible impact of over abstraction of water on the low flow component of IFR.

The general approach to the quantification of the groundwater contribution to surface water is numerical simulation. However the numerical results often suffer from lack of measured groundwater

* To whom all correspondence should be addressed.

盄 021 959-3882; fax 021 959-2438; e-mail: yxu@uwc.ac.za

Received 15 February 2002; accepted in revised form 7 August 2002. flow data for calibration. Alternatively, hydrograph-separation techniques are used in South Africa. It is commonly accepted that a hydrograph consists of baseflow (groundwater), interflow and direct runoff. The hydrograph-separation techniques are used to separate baseflow from a hydrograph by removing quick (or high) flow from slow (or low) flow (Smakhtin, 2001). Many researchers have focused on hydrograph-separation for short period events such as a single flood (Linsley et al., 1958; Farvolden, 1964; Rorabaugh, 1964; Halford and Mayer, 2000). Automation of hydrograph-separation methods has made their techniques easier to apply for larger time scales (Rutledge, 1993; Mayer and Jones, 1996). However, as Halford and Mayer (2000) point out, all hydrograph-separation techniques, when used alone, are poor tools for estimating groundwater discharge because the major assumptions of the techniques are not easily met. In South Africa, Herold (1980) suggests that the current groundwater component results from the combined effect of decay of previous groundwater discharge and previous streamflow increase. This method was adopted in the Water Resources 1990 project in South Africa, in which a time series of monthly flows could be separated into surface and groundwater components for each of the approximately 2000 Quaternary catchments of the study area (South Africa, Lesotho and Swaziland) (Vegter and Pitman, 1996). Even though the Herold method is an improvement on earlier hydrograph-separation techniques, it is still very subjective and does not take hydrogeological settings into account. Existing hydrograph-separation methods used in South Africa are summarised in Table 1.

These methods often seem to be unable to differentiate the origins of the low flow component that may contain groundwater discharge as well as interflow. Questions like; what portion of low flow is groundwater and to what degree groundwater contributes to instream flow requirements (IFRs) remain unresolved.

The understanding of the mechanism of baseflow generation in rivers is a prerequisite for the estimation of any realistic time series 


\begin{tabular}{|c|c|c|}
\hline \multicolumn{3}{|c|}{$\begin{array}{c}\text { TABLE 1 } \\
\text { Hydrograph-separation techniques }\end{array}$} \\
\hline Method & Status & Confidence \\
\hline RCD-method (Rorabaugh, 1964; Rutledge, 1993) & Not applied & Medium to high \\
\hline Concentration ratio (Freeze and Cherry, 1979) & Good for interflow & Low to high \\
\hline Herold (1980) & Acceptable & Low to high \\
\hline SARES (Hughes and Münster, 1999) & Applied for ecological reserve & Low to medium \\
\hline Smakhtin (2001) & Acceptable & Low to medium \\
\hline
\end{tabular}

of groundwater discharge into rivers. Traditionally, a hydrogeological approach is initially aimed at understanding groundwater occurrences, the delineation of aquifer boundary conditions, and eventually, the determination of the relationship between groundwater and surface water bodies. However, this approach tends to be qualitative and not useful for generating groundwater discharge time series. Alternatively, numerical simulation techniques are often employed to generate groundwater discharge time series. However, this often requires calibration data and has cost implications. To overcome these drawbacks, this paper proposes an alternative approach based on the geomorphic features of streams and introduces a procedure that makes use of hydrogeologic rules for consistency of the separation during the generation of time series at monthly intervals. These simple rules are easily implemented in spreadsheets, to achieve the preliminary estimation of the time series of groundwater discharge to a surface water body.

\section{Hydrogeomorphological classification of streams}

Streams may be classified based on various criteria for different purposes. For the purposes of ecological reserve determination, it is important to characterise a stream by its geomorphic features during hydrogeological investigations. The following geomorphologic classification is adopted for quantification of groundwater discharge towards streams (Xu et al., 2001a).

\section{Geomorphological classification of streams}

The following general classification for streams may be recognised in South Africa:

- Upper catchment areas

- Steep profiles

- Deep incision

- Inflow from valley sides in humid areas

- Large bedloads

- Middle courses

- Bedload deposition

- Braided channels near mountains

- Neotectonic uplift creates an incised convex profile downstream with riffle and pool sequences

- A few meandering rivers in stable areas in South Africa (e.g. Klip River)

- Lower courses

- Neotectonic uplift causes incision, especially of old meanders

- In the arid west rivers are allogenic, with deeper bed deposits and thicker terraces

- In estuaries sea level change results in deep infills with some saline intrusion
- Meanders on wide coastal plains (e.g. Pongola)

- Special cases of endoreic drainage intolarge pans (e.g. Okavango River)

The above geomorphological classification provides hydrogeologists with information that is related not only to what type of aquifer is being dealt with, but also to what type of boundary conditions one should take into account in the conceptualisation of aquifer systems. In general, the implications for groundwater interactions with streams (rivers) may be summarised as follows:

- Upper catchment areas

Type a: Streams without bank storage (e.g. braided rivers). This type is most likely to occur in mountainous areas. Streamflow possesses sufficient energy to incise the stream channel resulting in cliffs on either side. At local scale subsurface stormflow (or interflow) could seep out into the stream, but at regional scale this is the recharge area for groundwater systems.

- Middle courses

Type b: Streams controlled by bed morphology (e.g. pool and riffle sequences). This type is often associated with, but not restricted to, the above Type a. Although the interaction with groundwater due to bed morphology alone is very localised, interaction with groundwater at a regional scale can be significant. It can be of a recharge or discharge nature for an aquifer system. At a regional scale this is a groundwater runoff area, while at a local scale the direction of interaction between groundwater and river may be changeable.

- Lower courses

Type c: Streams with bank storage (e.g. meandering rivers). This type often appears in topographically flat areas near a regional base level. Fluvial erosion is able to develop terrain horizontally, and these areas may become a bank storage buffer for groundwater. Generally, this is the discharge area for regional groundwater systems. It is important to note that the role of bank storage is significant only if the bank is composed of unconsolidated sediments with a good storage coefficient. Type d: Streams influenced by channel morphology. This type is often associated with, but not restricted to the above Type c. Interaction with groundwater due to channel morphology is at intermediate scale. It is often of a discharge nature for a regional groundwater system.

- Special cases

Type e: Streams dictated by geological structures, especially those caused by neotectonic movements. Occurrence and interaction with groundwater is site specific.

Type f: Streams with headwaters originating from allogenic source (e.g. Molopo River). This type often occurs in the drier western parts of the country, where streams are of an ephemeral nature. When a big flood comes, it would recharge aquifers. 
The major advantage of this classification is that each stream type can be associated with a particular geomorphologic and hydrogeological setting, including flow boundary conditions and the ecological significance of these groundwater flows.

\section{Interaction types and characteristics}

From a hydrogeomorphological point of view, four types of interactions between streams and groundwater can be recognised. Let us begin with a general case for the purpose of understanding the terminology used.

\section{Separation for a single flood event}

A single peak flow is illustrated in Fig 1. The hydrographseparation method makes use of the following terms. Hydrograph-separation is used to divide hydrograph into two parts: quick runoff and slow flow (mainly groundwater component). The latter is controlled by the hydrogeological conditions upstream and in the vicinity of the stream channel. Time parameter $\mathrm{T}$ (d) can be determined based on existing methods (Linsley et al., 1958; Rorabaugh ,1964; Domenico and Schwartz, 1990), although they may be based on empirical relations. Point A: starting of baseflow recession; Point B: recession point at peak flow; and Point $\mathrm{C}$ : quick runoff terminated after $\mathrm{T}$ time.

\section{Hydrogeomorphological typing}

There are still some difficulties regarding how to accurately separate groundwater discharge from hydrographs. For instance, a monthly time-scale is normally used rather than a daily scale for the separation. However, a rule of thumb may be proposed to assist with the separation process. The following four types of interactions between streams and groundwater can be conceptualised.

\section{Type 1: Constantly losing or gaining streams}

This type may occur in the upper catchment where the regional groundwater level is constantly below the stream stage as shown in Fig. 2 (1a). It may also be found in places where permeabilities of stream bed materials are such that the amount of water lost from streams is limited. Constantly gaining streams may also exist where streams are fed by groundwater from confined aquifers (case 1b of Fig. 2).

\section{Type 2: Intermittent streams}

This type may be found in the middle course where groundwater discharges towards the stream during dry periods, while the river recharges aquifers during floods. The baseflow component would have a cutoff under the peak flow time as in case 2 of Fig. 2.

\section{Type 3: Gaining streams with or without storage}

This type is often observed in the lower course where groundwater levels may be consistently higher than the river stage. The baseflow component would increase in either an S curve or a straight line, depending on the presence of bank storage. As shown in Fig. 2, the three possible cases are: $3 \mathrm{a}$ for porous media without bank storage, $3 \mathrm{~b}$ for fractured media without bank storage and $3 \mathrm{c}$ for fractured media with storage.

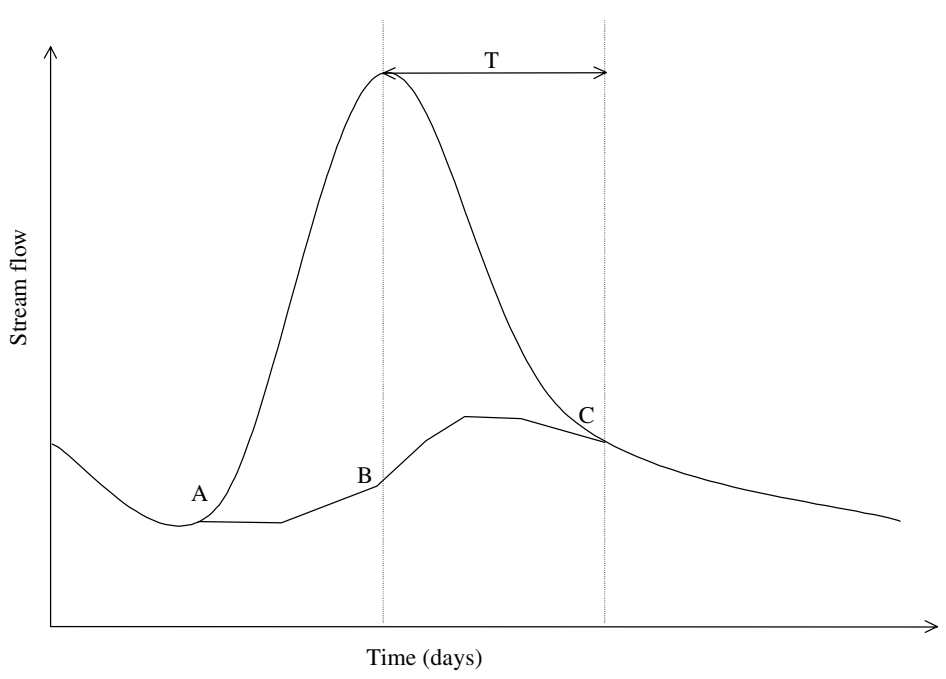

Figure 1

A single peak flow

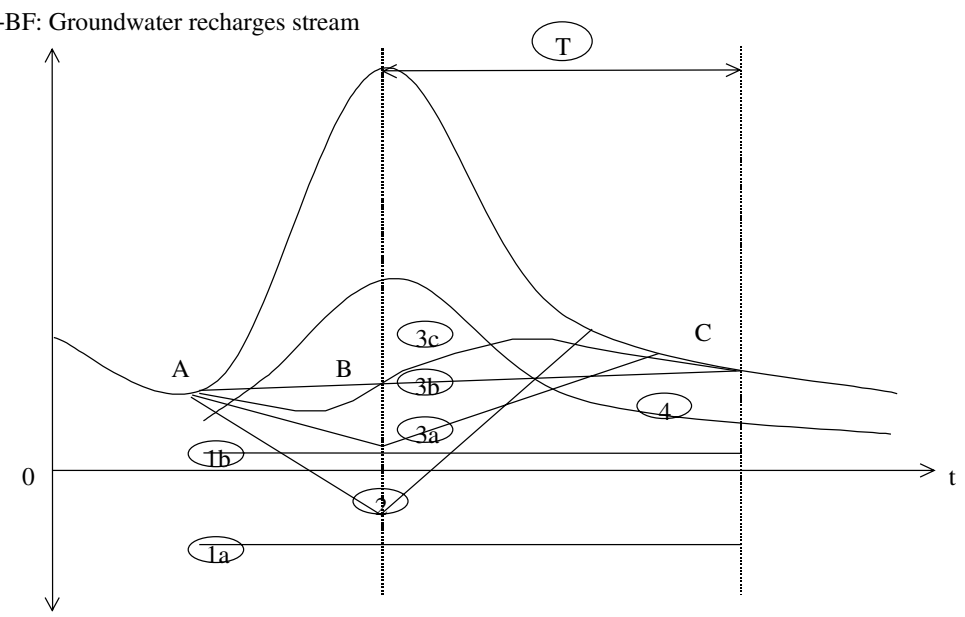

BF: Stream recharges groundwater

Figure 2

Typical scenarios of the interaction between groundwater and steams

\section{Type 4: Interflow-dominant streams}

This type may occur in the upper catchment where interflow may be the dominant component of stream hydrographs. If the regional groundwater level is below the stream stage, traditional separation techniques would give an indication of the magnitude of interflow contribution. It may also be complicated by geological structures in some cases. As shown in Fig. 2, the baseflow displays similarities to the quick runoff in terms of their phase and amplitude.

\section{Summary}

In terms of hydraulic connection, the above types of interactions between streams and groundwater can be summarised as follows (Fig. 3, Table 2).

\section{Generation of discharge time series}

An algorithm for the estimation of monthly groundwater discharge is proposed for the Types 1 through 3 of Fig. 3. It is assumed that 


\section{Hydrogeomorphologic Types}

- Geomorpho

Type 1: upper

Type 2: middle

Type 3: lower

logic typing

catchment

course

catchment

Type 4: Special cases

- Interaction

scenarios

Interflow dominan

Intermittent in

Groundwater

discharge zone

Under some

circumstances

Figure 3

An illustration of the different relationship between rivers and

groundwater
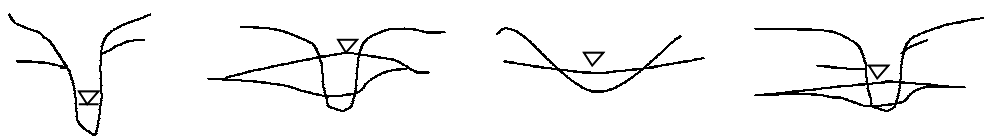

- Baseflow separation concept
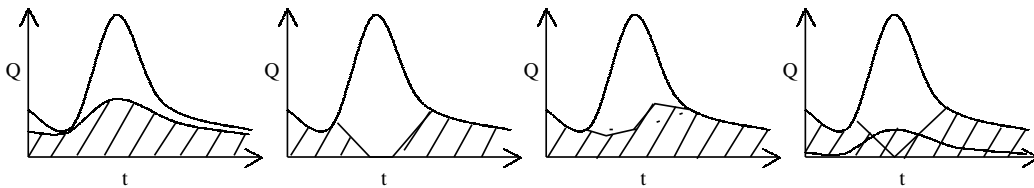

TABLE 2

Types of interaction between groundwater and rivers

\begin{tabular}{|c|l|c|c|c|c|}
\hline Type & Nature of Interaction & $\begin{array}{c}\text { Geomorpho- } \\
\text { logical Type } \\
\text { as in Fig 2 }\end{array}$ & $\boldsymbol{Q}_{g 0}$ & $\boldsymbol{D}$ & $\boldsymbol{I}$ \\
\hline $\mathbf{1}$ & $\begin{array}{l}\text { Constant losing streams (constant gaining streams) } \\
\mathbf{2}\end{array}$ & $\begin{array}{c}\text { Intermittent streams } \\
\mathbf{2},(1 \mathrm{~b})\end{array}$ & $\begin{array}{c}-,(+) \\
+,-\end{array}$ & $\begin{array}{c}1,(1) \\
+\end{array}$ & $\begin{array}{c}- \\
+\end{array}$ \\
$\mathbf{3}$ & Gaining streams as WL > stage (with storage) & $\begin{array}{c}3 \mathrm{a}, 3 \mathrm{~b},(3 \mathrm{c}) \\
+,+,(+)\end{array}$ & $\begin{array}{c}1,+,(<) \\
0.34 \sim 0.66, \\
0.67 \sim 1, \\
\mathbf{4}\end{array}$ & $\begin{array}{c}0.01 \sim 0.33) \\
+\end{array}$ \\
\hline
\end{tabular}

the lumped parameter approach is adequate for the purpose of generating monthly groundwater time series under the hydrogeomorphological framework.

\section{Hydrogeomorphological approach}

\section{Adaptation of formula}

The hydrogeomorphological approach to the quantification of groundwater contributions allows qualitative knowledge of field problems to be incorporated into hydrograph analyses. Modified from Herold (1980), it is proposed that the groundwater contribution to baseflow be a summation of the decay of previous groundwater contribution $\left(Q_{g i-l} * D\right)$ and rainfall-induced flow increment $\left(Q_{i-l} * I\right)$. This may be written as:

$$
\begin{aligned}
Q_{g i} & =Q_{g i-1} \cdot D+Q_{i-1} \cdot I \\
& =\left(Q_{g i-2} \cdot D+Q_{i-2} \cdot I\right) \cdot D+Q_{i-1} \cdot I \\
& =Q_{g 0} \cdot D^{i}+Q_{0} \cdot I \cdot D^{i-1}+\ldots Q_{i-j} \cdot I \cdot D^{j-1} \ldots+Q_{i-2} \cdot I \cdot D+Q_{i-1} \cdot I \\
& =Q_{g 0} \cdot D^{i}+\left(\sum_{j=1}^{i} Q_{i-j} \cdot D^{j-1}\right) \cdot I
\end{aligned}
$$

where $Q_{g 0}$ is an initial or average groundwater contribution.

Eq. (1) indicates that baseflow $Q_{p i}$ is a function of $Q_{o 0}$ and $Q_{i}$ with parameters $I(-1 \sim 1), D(0 \sim 1)$. Different ranges of these values can be specified for different types of groundwater and surface water interactions. The following rules are proposed in Table 2 when use of Eq. (1) is made.

The proposed method makes use of the following assumptions:

- Groundwater discharge fluctuation is of the same order of magnitude as spring flows. Thus some limits may be imposed on $Q_{g i}$, e.g. $Q_{g M i n}<Q_{g i}<Q_{g M a x}$ based on spring flow fluctuation in the catchment.

- The influence of instream materials and geometry is negligible.

- A direct correlation exists between groundwater recharge events and stream discharge peaks.

\section{Estimation of parameters}

The value of $Q_{g 0}$ may represent a long-term balance of the interaction. To estimate the value of $Q_{g 0}$, it is proposed that use of the water table contour maps be made. Either Darcy's law or a numerical model can be used to estimate groundwater flux towards streams. For numerical simulation, any model can be used as a computational tool with following steps (Zhang, 2000):

- Discretise the study area:

The study area is subdivided into finite-difference or finiteelement blocks, with the size of the blocks depending on the size of the study area and the desired resolution.

- Assign the measured groundwater level into each block:

Generally, the observed water levels are only available at some discrete points, and an interpolation method must be used to 


\section{Baseflow Separation}

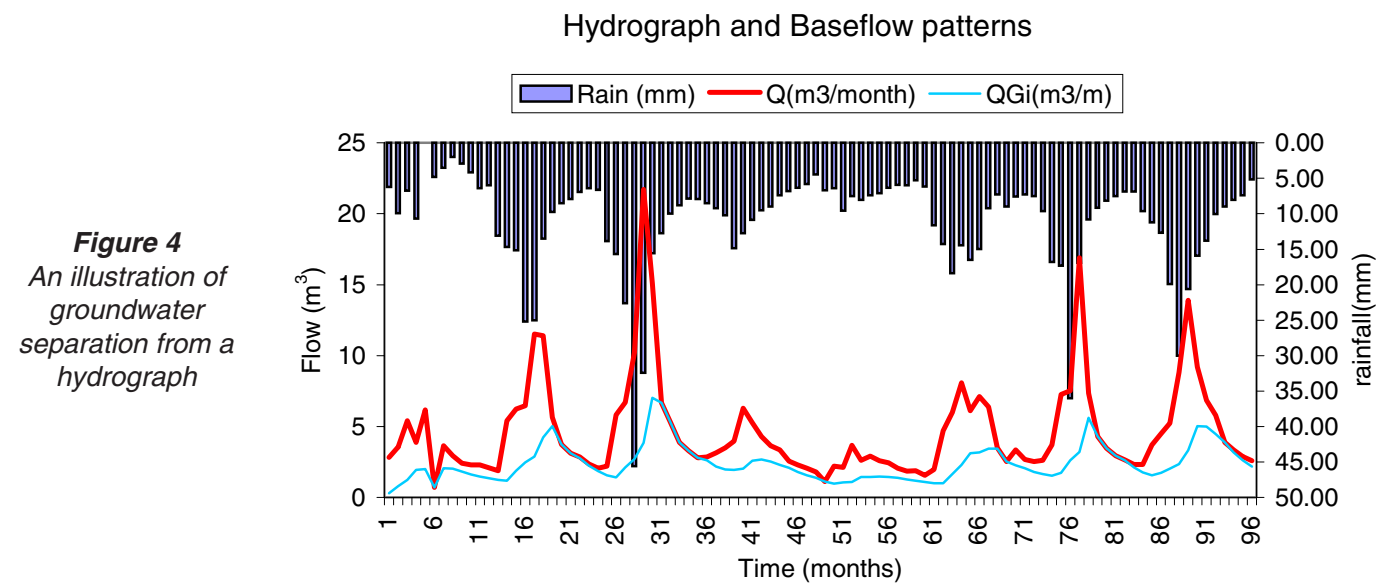

obtain the water levels for all blocks within the study area. If the groundwater levels are well correlated with the topography, the interpolation program TRIPOL (Van Tonder et al., 1996) is a good choice. Otherwise, interpolation methods such as Kriging can be used.

- Assign transmissivity values or hydraulic conductivity values and aquifer thickness to each block.

- Assign a high storage value to each block:

When a high storage value, say 1.0, is used, the water level of each block will only change very slightly during a flow "simulation". This ensures that the measured water level will be used for the flux calculation (see Step 6 below).

- Perform the transient flow simulation for one second:

The model calculates and saves the subsurface fluxes between each finite-difference block.

- Calculate the interaction flux $\left(Q_{g 0}\right)$ between groundwater and surface water.

\section{Interflow identification}

To simulate interflow, first thing to do is to make sure that any dominance of interflow in a specific site is identified. Interflow generally occurs under the following circumstances:

- Soil horizons act as flow barriers, which hinder a direct downward percolation of precipitation.

- A partially saturated flow may be formed via a perched water table.

- In the unsaturated zone interflow occurs along preferential flowpaths.

- Favourable geometric configuration of fractured networks may lead to formulation of interflow towards the river.

The interflow component should be substracted from baseflow to obtain reasonable groundwater contribution to the instream flow.

\section{Procedures}

A generic procedure is explained as follows:

- Conduct a field visit and collect information on borehole water level, etc.

- Establish the interaction relation between groundwater and surface water bodies. This entails identification of the interactive Types.

- Estimate recharge by using various tools, such as CRD method (Xu and Van Tonder, 2001).
- Compile a water-table contour or generate a contour map for a steady state using numeric model. Using numerical model generates value of $Q_{g 0}$.

- Achieve reasonable quantification of groundwater discharge to streams. The calibration can be done through comparison with a known recharge figure.

- Assess whether or not the instream flow requirement is met by taking into account possible abstraction.

\section{Spreadsheet program}

A program that is able to accommodate different interaction types is implemented in Excel spreadsheets. Microsoft Excel is recommended because of its simplicity and easiness of programming. The program implemented in the Excel workbook is available at the site: http://www.science.uwc.ac.za/earthscience/ index.htm. Three problems need attention:

- Data transfer: Text files from CD-Rom of WR90 can be directly copied to Excel spreadsheet by using Visual Basic Application (VBA) modules.

- Interface can be enhanced by VBA supported visual Buttons.

- Combination of various graphic features can be formulated through VBA or Macros.

\section{Example}

The Excel workbook is able to accommodate different interaction types. As an example of separation of the groundwater component from a hydrograph, a hydrograph of quaternary catchment X31A of the Sabie River is used to illustrate the application of the Excel program.

Hydrogeomorphological features indicate the following:

- The Sabie River is gaining water from aquifers along its river course.

- River bank has storage that would regulate exchange of water between the Sabie River and aquifers in vicinity.

Based on the discussion in Table 2, parameters $D$ and $I$ may be taken as 0.75 and 0.25 , respectively. The value of $Q_{00}$ could be estimated using a numerical simulation as proposed. But in this case the lowest value of the hydrograph can be used as the first value, i.e. $Q_{g 0}$ $=0.712 \mathrm{~m}^{3} /$ month. The separation result is shown in Fig 4. This separation yields a ratio of groundwater discharge to direct runoff 
at $49.17 \%$. This result is comparable with that presented by Vegter (1995).

It is possible to derive recharge values based on the amount of groundwater separated from the hydrograph (Vegter, 1995). The idea is to convert the separated groundwater component into an equivalent groundwater runoff value, which can be compared to the surface water runoff. In this case the recharge is estimated at $14 \%$ of precipitation.

\section{Discussion}

The Excel program is user-friendly. However, to prevent it from being misused, hydrogeomorphological typing of specific sites must be carried out in order to apply the suggested rules correctly. For the purposes of possible applications, attention should be paid to the following points.

- The groundwater contribution from the proposed method is conservative because evapotranspiration from the saturated zone along the stream valley is neglected.

- Chemical concentrations should be used to check or confirm the quantification of the groundwater component.

- The significance of isotope methods should be examined.

Ecosystems are dependent on natural flow variability. If the natural flow is constant, problems can be expected. The reserve (IFRs in the case of rivers) does not refer only to volume but also to duration, frequency and timing. Therefore the generated groundwater time series may necessarily be inaccurate. But it must reflect the flow dynamics to an order of magnitude accuracy, as real groundwater discharge series would have. Similar to the surface water approach, assurance analysis of the generated groundwater contribution is required by presenting a duration curve.

One of the critical issues for the assignment of an annual IFR values into monthly IFR values is how to evaluate the groundwater contribution to baseflow. A hydrogeologist involved in the Reserve study must investigate and establish the relationship between groundwater and surface water bodies in order to fully understand the hydrogeological implications of the IFRs.

\section{Conclusions}

The proposed empirical approach is based on an hydrogeomorphological understanding and should be applied with caution. This approach attempts to first recognise typical geomorphologic stages of streams and relate them to hydrogeological settings, and then adopt relevant algorithms to estimate the discharge time series. Although still subjective in nature, the hydrogeomorphological approach is able to give a range of values of what the groundwater discharge is likely to be.

Owing to the fact that field problems are very complicated, the accurate calculation of the groundwater contribution to streams is difficult. Although the proposed approach still needs verification and improvement through case studies, it makes simple hydrographseparation techniques more meaningful. This provides a good conceptual framework where time series of groundwater discharge to streams can be estimated with reasonable (order of magnitude) accuracy. Much more investigation still needs to be done in order to refine the methodology.

\section{Acknowledgements}

The hydrogeomorphological idea was presented by the principal author in a WRC sponsored workshop on surface water and groundwater interaction held in Pietermaritzburg in November 2000. The constructive comment from the workshop participants is acknowledged. The author benefits from discussion with Professor J Shao of the China University of Geosciences, Beijing. The Water Research Commission (WRC) is thanked for supporting this study and allowing publication of the work.

\section{References}

DOMENICO PA and SCHWARTZ FW (1990) Physical and Chemical Hydrogeology. John Wiley \& Sons, Inc.

FARVOLDEN RN (1964) Geologic controls on groundwater storage and base flow. J. Hydrol. 1 219-250.

FREEZE RA and CHERRY JA (1979) Groundwater. Pretice-Hall, Inc.

HALFORD KJ and MAYER GC (2000) Problems associated with estimating groundwater discharge and recharge from stream-discharge records. Ground Water 38 (3).

HEROLD CE (1980) A Model to Compute on a Monthly Basis Diffuse Salt Loads Associated with Runoff. WRC PWVS project, HRU Report No. $1 / 80$.

HUGHES DA and MÜNSTER F (1999) A Decision Support System for an Initial 'Low-Confidence' Estimate of the Quantity Component of the Reserve for Rivers. Institute for Water Research, Rhodes University, South Africa.

LINSLEY RK, KOHLER MA and PAULHUS JLH (1958) Hydrology for Engineers. New York, McGraw-Hill.

MAYER GC and JONES LE (1996) SWGW - A Computer Program for Estimating Groundwater Discharge to a Stream Using Streamflow Data. USGS WRI 96-1071.

RORABAUGH MI (1964) Estimating Changes in Bank Storage and Groundwater Contribution to Streamflow. Int. Assoc. of Sci. Hydrol. Publication 63 432-441.

RUTLEDGE AT (1993) Computer programs for describing the recession of ground-water discharge and for estimating mean ground-water recharge and discharge from streamflow records. Ground Water 32 (2) 180-189.

SMAKHTIN VU (2001) Estimating continuous monthly baseflow time series and their possible applications in the context of the ecological reserve. Water SA 27 (2) 213-217.

VAN TONDER GJ, VAN SANDWYK L and BUYS J (1996) Program TRIPOL, Version 1.0, Institute for Groundwater studies, and Water Research Commision.

VEGTER JR (1995) An Explanation of a Set of National Groundwater Maps. Report No. TT 74/95, Water Research Commission, Pretoria.

VEGTER JR and PITMAN WV (1996) Recharge and stream flow. Workshop on Groundwater - Surface Water Issues in Arid and Semi-arid Areas. Organised by the Water Research Commission and IAH (South Africa), Pretoria.

XU Y and VAN TONDER GJ (2001) Estimation of recharge using a revised CRD method. Water SA 27 (3) 341-343.

XU Y, COLVIN C, VAN TONDER GJ, LE MAITRE D, ZHANG J, BRAUNE E and PIETERSEN K (2001b) Determination of Resource Directed Measures: Groundwater Component (Version 1.1). WRC Project Report (K5/1901-2), Water Research Commission, Pretoria.

XU Y, MAFANYA T, VAN TONDER GJ and PARTRIDGE T (2001a) Estimation of monthly groundwater discharge time series under simplified hydrogeological scenarios in South Africa. Proc. of the 10th S. Afr. Natl. Hydrol. Symp., Pietermaritzburg, 26-28 September 2001. Website: http://www.beeh.unp.ac.za.

ZHANG J (2000) Estimation of the Preliminary Groundwater Reserve Using Numerical Models. M.Sc. Thesis, Inst. for Groundwater Studies, Univ. of the Free State. 